\title{
El problema del crecimiento económico en la Europa moderna: del eurocentrismo al asiacentrismo y policentrismo
}

\author{
The problem of economic growth \\ in Early Modern Europe: From Eurocentric \\ to asia-centric and polycentric perspecives
}

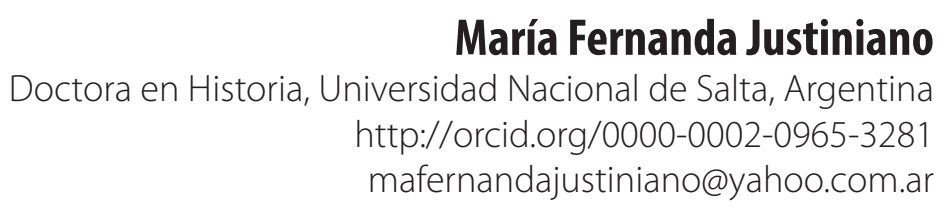

Fecha de recepción: 15 de julio de 2015 Fecha de aceptación: 20 de diciembre de 2015

Sugerencia de citación: Justiniano, M.F. (2016). El problema del crecimiento económico en la Europa moderna: del eurocentrismo al asiacentrismo y policentrismo

tiempo\&economía, 3(1), 19-37, doi: http://dx.doi.org/10.21789/24222704.1093

\section{Resumen}

La historiografía de los últimos treinta años ha modificado sustancialmente los conocimientos sobre la historia económica de los tiempos modernos. Los enfoques basados en la "excepcionalidad" del proceso histórico europeo, o el "milagro" económico, o "la vía única de la civilización occidental", vienen siendo confrontados.

Este artículo pretende dar cuenta del estado actual de las principales discusiones, a partir de identificar las principales contribuciones de los historiadores económicos que revierten los grandes constructos historiográficos establecidos por la historia económica de los siglos XIX y XX sobre el crecimiento económico durante la Edad Moderna. 
Palabras clave: Historia económica historia moderna, historiografía crecimiento económico. Códigos JEL: B2, N00, N010, N100

\begin{abstract}
The historiography of the last thirty years has substantially altered the knowledge on the economic history of early modern times. Approaches based on the "uniqueness" of European historical process, or economic "miracle" or "the only way of Western civilization" are being confronted.

This paper seeks to explain the current state of the main discussions, from identifying the main contributions of the economic historians that reverse the great historiographical constructs established by the economic history of the nineteenth and twentieth centuries about the economic growth during the Early Modern Age.
\end{abstract}

Keywords: Economic History, Early Modern History, Historiography, Economic Growth.

JEL Codes: B2, N00, N010, N100 


\section{Introducción}

La historia económica y su historiografía no fueron inmunes al profundo resquebrajamiento de los modos de conocer acaecido en las últimas tres décadas del siglo XX. En menos de cuarenta años se desmoronaron los grandes metarrelatos erigidos por las ciencias sociales decimonónicas, que fueron afirmados en la centuria siguiente. La exposición histórica escrita referida a la historia económica de la Edad Moderna fue la más afectada de esta crisis de la perspectiva de la simplicidad y el ascenso del pensamiento complejo.

A modo de ejemplo, y para hacer gráfica esta afirmación, la expresión Edad Moderna, en estas últimas cuatro décadas, dejó de ser un sustantivo que hacía referencia a una realidad europea que se imponía como universal, para convertirse en un adjetivo de múltiples espacios. La declinación del eurocentrismo que caracterizó a los grandes enfoques elaborados sobre el mundo de los siglos XVI al XVIII fue una muestra de este cambio de enfoques. Los nuevos estudios en materia de historia económica cuestionaron seriamente el papel central del Occidente europeo en el devenir histórico moderno. Una Edad Moderna Global, Asiacéntrica y/o Policéntrica comenzó a tomar forma desde hace más de una década.

Este artículo se propone dar cuenta de estas profundas mudanzas de perspectivas en el conocimiento construido sobre la historia económica de los tiempos modernos. Se ha elegido como eje articulador del análisis el crecimiento económico, por cuanto es el tópico que articula y moldea la producción disciplinar del siglo pasado y del actual. Aunque, como se verá en las páginas que siguen, las preocupaciones en las últimas décadas se han desplazado hacia temáticas como niveles de vida, nuevas vías hacia la industrialización, cuándo y cómo se produce la brecha entre Oriente y Occidente. Se trabajará con obras de historia económica que han contribuido a consolidar o romper determinados paradigmas, modelos o propuestas interpretativos. ${ }^{1}$

\section{Smith, Marx, Weber, y la vía única europea}

Estos cambios de visión son el resultado de un profundo quiebre epistemológico y metodológico en la disciplina historia económica, que no implicó la renuncia al interrogante sobre por qué crecen las naciones. Pregunta que mantiene su rol de pivote en los estudios sobre el pasado económico, tal como lo estableció hace más de doscientos años Adam Smith en su obra cumbre Investigación de la naturaleza y causas de la riqueza de las naciones, publicada en 1776 bajo el título An Inquiry into the Nature and Causes of the Wealth of Nations.

Ya a fines del siglo XVIII, este filósofo escocés, considerado el padre de la Economía, había dejado sentado que, entre las naciones de su tiempo, las más prósperas eran las europeas. El punto de comparación, en aquel entonces, era la lejana China.

La superioridad de Europa era caracterizada y explicada del siguiente modo por el autor de La Teoría de los Sentimientos Morales:

1 Agradezco a los evaluadores las sugerencias y aportes realizados que han contribuido a enriquecer este artículo. Aunque soy la única responsable de la versión final que aquí se presenta.

tiempo\&economía

Vol. 3 N 1 - I semestre de 2016

p. 21 
La China ha sido muchos tiempos uno de los países más ricos, esto es mas fértiles, mas cultivados, más industriosos y más poblados del mundo; pero también parece haber estado muchos tiempos estacionario, o sin adelantar mas y mas. Marco Polo que los visitó más de quinientos años hace describe su cultivo, su industria y su población casi en los mismos términos que los viajeros de nuestra era. Y acaso quando Polo los vió, habría ya mucho tiempo que habían adquirido aquella plenitud de riquezas que les permitían sus leyes y su constitucion. Las relaciones de todos los viajeros, aunque varias en otros puntos, convienen en lo baxo de los salarios del trabajo en aquella región, y en la dificultad con que un trabajador Chino podía mantener su familia. Qualquiera de ellos se contenta con haber adquirido á la noche un poco de arroz después de haber estado trabajando todo un dia. Aun es peor si cabe, la condición de un artesano. En vez de esperar descuidadamente en sus talleres que les busquen sus parroquianos, como sucede en Europa, tienen que andar continuamente por las calles con los instrumentos de sus oficios respectivos, ofreciendo en servicio, y casi indignado la labor. No hay en Europa nación tan pobre que pueda comparar su miseria con la de la clase inferior de un pueblo de la China. Se asegura generalmente que en las inmediaciones á Cantón hay centenares y aun millares de familias que no conocen habitación en tierra, que se ven reducidos á vivir habitualmente en pequeños Barcos ó Canoas dentro - de los ríos y canales. El alimento lo encuentran con tanta dificultad que riñen por coger los desperdicios que se arrojan al agua del bordo de las embarcaciones Europeas. Un perro muerto ó otro animal pestífero es para ellos un manjar igual al del mas delicado alimento en otros países. (1805, p. 129)

En estas líneas de Smith encontramos muchos de los supuestos establecidos por la historia económica de los siglos XIX y XX. El primero y más fuerte por destacar es el del convencimiento de una superioridad europea. Puede afirmarse que la mayoría de las investigaciones han procurado en los últimos doscientos años dar cuenta de por qué el derrotero seguido por Europa occidental fue único y exitoso, en términos del progreso decimonónico.

Las producciones de los últimos dos siglos coincidieron mayoritariamente en que fueron las propias condiciones generadas dentro de Europa las que procuraron este camino excepcional de crecimiento. El Occidente europeo contaba con las instituciones más eficaces frente al resto. El Estado racional, en el sentido weberiano, era una de ellas. Para Max Weber (1996), era este Estado - que solo se da en Occidente, y en el cual se fundan la burocracia profesional y el derecho racional- el único donde podía prosperar el capitalismo moderno (p. 1048). Afirmación que escribió en su célebre obra Economía y sociedad, cuya primera edición en alemán fue en 1922.

Tal como Smith lo había hecho ciento cuarenta y seis años antes, el sociólogo alemán también recurrió a la comparación de Europa con China. A su juicio, en esta última el ascenso del Estado racional se vio impedido por la fuerza de la magia. Existía en el Estado chino una concepción mágica de que la virtud del emperador y de los funcionarios, o sea su superioridad en materia literaria, bastaba para mantenerlo todo en orden (p. 1047).

El derecho romano fue, paraWeber, otra institución trascendente para explicar la originalidad europea y el surgimiento del capitalismo, por cuanto lo considera responsable de la creación del pensamiento jurídico-formal (p. 1049). Nuevamente la compara con China, y entiende que 
aquí el capitalismo no podía operar, por cuanto tenían un papel importante los puntos de vista religioso-rituales y mágicos (p. 1050).

La siguiente frase de Max Weber resume lo afirmado en párrafos anteriores:

En cambio, el Occidente disponía de un derecho formalmente estructurado, producto del genio romano, y los funcionarios formados a base de dicho derecho se revelaron, en cuanto técnicos de la administración, como superiores a todos los demás. Desde el punto de vista de la historia económica, este hecho adquirió importancia, porque la alianza entre el Estado y la jurisprudencia formal había de favorecer al capitalismo.

Una política económica estatal digna de este nombre, o sea una política continuada y consecuente, solo se origina en la época moderna. El primer sistema que se produce es el llamado mercantilismo. Anteriormente al mismo, sin embargo, había por doquier dos cosas: política fiscal y política del bienestar, en el sentido, esta última, del aseguramiento de la cantidad usual de alimentos. (p. 1050)

A comienzos del siglo XX, en la historia económica ya se había establecido un consenso hegemónico que tenía como axioma la superioridad de Europa producto de la peculiaridad de sus instituciones, únicas capaces de dar a luz al capitalismo.

Karl Marx, sin cuestionar la superioridad europea, llamaba la atención sobre las relaciones de Europa y el resto del mundo. Para el activista y filósofo alemán, las colonias, tanto las Indias Orientales como las Occidentales, forman parte del punto de partida del régimen capitalista. De este modo, los siglos de la Edad Moderna coinciden con el proceso de acumulación originaria propuesto en la obra marxiana. Denominado así porque forma parte de la prehistoria del capital y del régimen capitalista de producción.

Para Marx, la acumulación originaria no es más que el proceso histórico de disociación entre el productor y los medios de producción (1946, p. 608). La historia colonial forma parte de las diversas etapas de la acumulación originaria, las cuales tienen su centro, en un orden cronológico más o menos preciso, en España, Portugal, Holanda, Francia e Inglaterra. Expresa Marx que en Inglaterra es donde, a fines del siglo XVII, se resumen y sintetizan sistemáticamente el sistema colonial, el sistema de deuda pública, el moderno sistema tributario y el sistema proteccionista. Todos ellos se valen del poder del Estado, de la fuerza concentrada y organizada de la sociedad, para acelerar a pasos agigantados el proceso de transformación del régimen feudal de producción en el régimen capitalista (pp. 638-639).

En el análisis marxiano, estos territorios extraeuropeos, pero integrados al continente como colonias, son parte del proceso de la génesis del capitalismo, aunque no centrales para su explicación. En el siguiente párrafo, difundido profusamente por el recientemente fallecido escritor uruguayo Eduardo Galeano (1971) en su célebre obra Las venas abiertas de América Latina, se transcribe parte del último planteo marxiano descrito (p. 25): 
El descubrimiento de los yacimientos de oro y plata de América, la cruzada de exterminio, esclavización y sepultamiento en las minas de la población aborigen, el comienzo de la conquista y el saqueo de las Indias Orientales, la conversión del continente africano en cazadero de esclavos negros: son todos hechos que señalan los albores de la era de producción capitalista. Estos procesos idílicos representan otros tantos factores fundamentales en el movimiento de la acumulación originaria. (Marx, 1946, p. 638)

Estos planteos no lograron instalarse como líneas explicativas, pero pese a ello atrajeron un selecto grupo de investigadores que los desarrolló con creces. Durante la segunda mitad del siglo XX tomó fuerza un enfoque crítico que consideró necesario incorporar en el análisis del crecimiento europeo las relaciones entre Europa y otras partes del mundo, caracterizadas por diversas formas de extracción colonial de los recursos. Esta perspectiva agrupa las contribuciones de Eric Williams (1944), André Gunder Frank (1969), Samír Amín (1975), Immanuel Wallerstein (1976), Blaut (1993), entre otros. Algunos de ellos serán analizados en las páginas posteriores.

A lo largo del siglo XX, algunos de los aportes iniciales que habían dado forma a las explicaciones del crecimiento de Europa y su superioridad económica fueron difuminándose. Las comparaciones con China se hicieron innecesarias, y también se hizo innecesario el papel de los espacios del globo no europeos. Ello acaeció en casi toda la historiografía occidental, incluida la marxista.

Una vía explicativa centrada en Europa emergió con fuerza, atrapada todavía por la convicción de que las fuerzas maltusianas marcaban el ritmo de una economía estancada y de una población al borde permanente del hambre durante la Edad Moderna. Desde este punto de vista, solo la Revolución Industrial rompería con este ciclo, convirtiéndose en el gran parteaguas de la historia de la humanidad, después de la Revolución Neolítica.

Numerosos fueron los historiadores económicos que desarrollaron estas perspectivas. Entre ellos puede destacarse el alemán Wilhelm Abel (1904-1985), quien, a diferencia de Marx y Engels, observó que la Revolución Industrial era la superación del estado de pauperización. Los historiadores marxistas británicos no escaparon a estos planteos, a la vez que explicaron la transición del feudalismo al capitalismo en los diferentes espacios nacionales. El francés Emmanuel Le Roy Ladurie fue otro de los que más abrevó al enfoque de un estancamiento económico, que solo se vería interrumpido a mediados del siglo XVIII (Van Zanden, 2001). También en esta línea puede situarse a Fernand Braudel, Michael Postan, E. A. Wrigley, solo para nombrar a los más conocidos (De Vries, 2001).

\section{Las grandes narrativas cuestionadas}

Estas líneas, desarrolladas con solidez después de la Primera Guerra Mundial y hasta el último cuarto del siglo XX, comenzaron a ser seriamente cuestionadas entre 1970 y 1980 . Entre los responsables de este cambio de perspectiva puede citarse al inglés Nick Crafts (1985), quien junto a Knick Harley (1982), a mediados de la década de 1980, produjeron un gran impacto sobre el estado de las interpretaciones de la Revolución Industrial. 
A juicio de ambos, a partir del estudio cuantitativo de la productividad en Gran Bretaña y Francia durante los siglos XVIII y XIX, el crecimiento económico habría sido más gradual que revolucionario. Esta reinterpretación de la Revolución Industrial fue respaldada con mediciones de las tasas de crecimiento de diversas industrias y de diferentes sectores de la economía, con el fin de medir el crecimiento de la economía británica entre 1760 y $1850{ }^{2}$

Los estudios del historiador económico alemán Alexander Gerschenkron (1962) sobre los patrones de desarrollo de la Revolución Industrial en Europa hicieron de sustento y contención de las aseveraciones de Crafts y Harley. La concepción de la existencia de una ruptura o discontinuidad a fines del siglo XVIII fue socavada por la historiografía de ambas márgenes del canal de La Mancha.

De esta forma, uno de los principales modelos históricos de crecimiento económico quedó invalidado. Nos referimos a las Etapas de crecimiento formuladas por el economista estadounidense Whitman Rostow en 1960. Este postulaba que, a las sociedades tradicionales caracterizadas por una economía de subsistencia, les seguían las condiciones para el despegue económico, que posteriormente, y de modo sucesivo, las conducirían a la industrialización y al consumo (pp. 4-16).

Las investigaciones en curso dieron un giro a las interpretaciones elaboradas por los historiadores económicos sobre la Edad Moderna. Cada vez menos estudiosos acordaban que los tiempos previos a la Revolución Industrial se habían caracterizado por un estancamiento económico y poblaciones al límite de la subsistencia. Eran más los convencidos de que cambios estructurales y graduales habían tenido lugar en las centurias previas.

El historiador holandés Jan de Vries (1979) fue uno de los primeros en argumentar a favor este cambio de perspectiva, y de este modo expresó sus argumentos:

Alrededor de mediados del sigloXVIII (yun poco antes en la cuenca del Mediterráneo) la economía europea entró en una nueva fase. Casi en todos los sitios una poderosa expansión demográfica reemplazó la estabilidad o decadencia de la era anterior. Los precios comenzaron a subir otra vez. Los precios y las rentas agrícolas, especialmente, se recobraron con viveza del abatimiento de los años 30 del siglo XVIII. No es que ya se acabaran las crisis de mortandad de corta duración ni las de subsistencias, pero las violentas fluctuaciones que habían estado afectando a la economía europea durante tanto tiempo se amortiguaron notablemente después de 1750. Estos choques dejaron de desempeñar un papel tan importante en marcar el ritmo de la vida económica.

2 Desde la década de 1990, el concepto de Revolución Industrial está a la defensiva. La aceleración del proceso, las condiciones que lo promovieron, su origen, entraron en profundos cuestionamientos. En síntesis, la Revolución Industrial es cada vez menos revolucionaria, menos inglesa, menos europea, más gradual, más occidental. Cada vez es menos explicada por la revolución agrícola y por la destrucción violenta de la economía medieval inglesa; y más, por la intensificación del trabajo en los hogares preindustriales, por la revolución del consumo, las microinvenciones y la disponibilidad energética.

La conjunción de demanda de bienes y mayor laboriosidad fue sintetizada por Jan De Vries (1994) como revolución industriosa. Sus inicios los remonta hasta el siglo XVI, cuando se expanden por Europa los productos americanos, algunos de ellos de alto poder adictivo.

tiempo\&economía

Vol. $3 \mathrm{~N}^{\circ} 1$ - I semestre de 2016

p. 25 
El factor más notable de todos es que el período siguiente a 1750 fue testigo de un crecimiento sin precedentes en la economía inglesa.

Debido a esta notable mejora que anunciaba el advenimiento de la Revolución Industrial, el período precedente se nos aparece bajo una nueva luz. Retrospectivamente considerado, ese periodo fue la última época de la Europa tradicional [...]

Dos evoluciones fueron sumamente notables: el aumento de la población en las áreas forestales y en las zonas de suelos poco fértiles a consecuencia de la industria rural, y la elaboración de una jerarquía de ciudades más claramente definidas [...] se levantó en el pináculo de la jerarquía una nueva clase de metrópolis de un tamaño e impacto económico sin precedentes.

[...] No hubo que esperar a la aparición de un sistema de fábrica para que entrase en vigor el principio de división del trabajo [...] Muchas regiones sintieron el impacto de la especialización agrícola o fueron testigos de la elaboración de un sistema de industria a domicilio en las zonas rurales.

[...] se edificó un mercado hipotecario, [...] un cierto tipo de mercado de capital se formó alrededor de los centros financieros de Ámsterdam y Londres [...] El mayor progreso se alcanzó en la formación de mercados de mano de obra.

Lo que en verdad distinguía a Inglaterra de sus competidores ya a principios del S XVIII era la baratura de su acceso a algunas materias primas [...] En consecuencia, Inglaterra tenía la economía mejor preparada para un rápido crecimiento en el siguiente siglo. (pp. 244-245)

Entre los cambios estructurales citados por estos nuevos estudios que reclaman una mirada gradualista sobre la Revolución Industrial pueden citarse los aportes de De Vries sobre el desarrollo urbano, las redes internacionales de comerciantes, la revolución industriosa; las contribuciones de Franklin Mendels respecto de la industrialización antes de la industrialización o protoindustrialización; las producciones de Ann Kussmaul en torno a los patrones nacionales de especialización; los estudios de Jan Lucassen sobre los mercados de trabajo.

Todos ellos dan cuenta de que los tiempos de la Edad Moderna son dinámicos, y renuncian a pensar en la concepción de la Revolución Industrial como ruptura (Van Zanden, 2001, pp. 67-68). También, a juicio de De Vries (1979), socavan los planteos marxianos que afirmaban que "el descubrimiento de los yacimientos de oro y plata de América, la cruzada de exterminio, esclavización y sepultamiento en las minas de la población aborigen, el comienzo de la conquista y el saqueo de las Indias Orientales, la conversión del continente africano en cazadero de esclavos negros, volvían a la madre patria y se convertían en capital"(Marx, 1946, p. 638). Para el historiador holandés, no era necesario explicar la rápida acumulación de capital de algunas regiones con "la idea de que unas ganancias especiales e inesperadas eran requisitos previos para el verdadero crecimiento capitalista". Para el autor, en este período se pueden encontrar muchos ejemplos de una rápida acumulación de capital por otras vías que permiten 
superar la debilidad de la economía europea, referente a la mala inversión y al derroche de capital en lo referente a su insuficiencia (pp. 213-216).

En el campo académico se extiende un consenso sobre un crecimiento gradual de la economía europea en tiempos previos a la cuestionada Revolución Industrial. El modelo occidental de matrimonio formulado por John Hajnal en 1965 se constituyó en la base de las nuevas interpretaciones, que afirmaban con mayor énfasis la originalidad de la vía europea y, por ende, las perspectivas eurocéntricas. De este modo, el retraso de la edad en el matrimonio pudo haber permitido que hombres y mujeres emplearan sus años más productivos en trabajar sin tener a su cargo la responsabilidad de mantener una familia, incrementándose las posibilidades de ahorro y, por lo tanto, del crecimiento económico moderno y la Revolución Industrial (Cachinero Sánchez, 1981, p. 34).

Estos estudios sobre el comportamiento demográfico europeo, a la par que renovaron los enfoques eurocéntricos construidos, los socavaron en los años setenta y ochenta del siglo XX. Después de aquel histórico Mayo del 68 francés, en el clima científico ya se insinuaban síntomas de incertidumbre. Era evidente que las teorías de la modernización en sus diferentes variantes, marxista, weberiana, habían fracasado. No había un camino único hacia el bienestar, la racionalidad y la industrialización.

En 1972 se popularizó el término protoindustrialización, acuñado por Franklin Mendels, que implica la existencia de una fase previa, aunque no necesaria, antes de la Revolución Industrial. Esta etapa se caracteriza por una expansión masiva de la actividad manufacturera en ciertas partes de Europa entre el siglo XVI y el XIX, cuyos productos son dirigidos al mercado de exportación. El autosostenimiento de esta espiral protoindustrial demandó un crecimiento demográfico a partir de la elevación del número de casamientos, además de la generación de capital, mano de obra, espíritu emprendedor, una agricultura comercial y consumidores que demandaran estos productos (Ogilvie, 2008).

La perspectiva marxista encontró nuevos aportes para la explicación de la transición del feudalismo al capitalismo en la obra de Robert Brenner, quien arremetió contra el llamado neomaltusianismo historiográfico y sus concepciones de un crecimiento económico moderno estancado. El historiador estadounidense halló que la estructura de clases agrarias incidía directamente en el desarrollo económico de la Europa preindustrial. De este modo explica por qué Inglaterra consiguió desarrollar el capitalismo agrario mediante la destrucción del campesinado, para dar pasos a la industrialización (Brenner, 1988).

Pese a este aparente fortalecimiento de la concepción de una única vía, los golpes a las grandes metanarrativas eurocéntricas estaban asestados. El relato ya no era lineal, los argumentos iniciales de la originalidad europea estaban en discusión, junto a los grandes relatos de los cuales formaban parte.

\section{El nacionalismo metodológico cuestionado}

A fines de la década de 1980 y mediados de 1990 había cambiado sustancialmente la mirada que teníamos sobre los tiempos modernos. Las respuestas sobre el porqué de la riqueza de algunas naciones se tornaron mucho más complejas y dejaron de ser taxativas. Sin embargo, 
se mantuvieron como denominadores comunes el nacionalismo metodológico —expresado en los estudios de caso de escala regional/nacional ${ }^{3}$ - y la centralidad europea, esta última afirmada con mayor convencimiento.

Un ejemplo de este cambio de perspectiva es la obra de Eric Jones titulada The European miracle. Environments, economies and geopolicts in the history of Europe and Asia, publicada en 1981. Allí, en concordancia con las investigaciones de la época que reclamaban un mundo moderno dinámico, el autor señaló que fue entre 1400 y 1800 cuando tuvieron lugar las profundas transformaciones políticas, tecnológicas y geográficas que hicieron de Europa el lugar de nacimiento del mundo industrial (2003, p. 225). Para Jones, fue el surgimiento del Estado-nación, una forma puramente europea posfeudal, exportada a otras partes del mundo, el que habría generado las condiciones de estabilidad necesarias para expandir el desarrollo y el crecimiento, y para la difusión de las mejores prácticas de tecnología y comercio (2003, p. $127,149)$.

Sin embargo, pese a estos planteos con recurrentes argumentos eurocéntricos, la obra de Jones trajo como novedad la introducción, de nuevo, del espacio asiático en el análisis, que venía equipado con una propuesta de análisis comparativo. Estas trayectorias habían tomado fuerza, después de la Segunda Guerra Mundial, en las explicaciones de larga duración del historiador francés Fernand Braudel. Fueron Braudel e Immanuel Wallerstein los responsables de dotar a la historiografía económica de las herramientas epistemológicas, metodológicas y empíricas que le permitieron superar las barreras de los análisis nacionales, aunque el utillaje de conocimientos de la época no les permitió desembarazarse de las tesis eurocéntricas.

Kenneth Pomeranz (2000) definió los argumentos del crecimiento económico de la Edad Moderna propuestos por Braudel como institucionalistas (p. 15). Afirmó que tanto el historiador francés como sus seguidores se ocuparon más de las ganancias acumuladas por un puñado de personas ricas. Señala que las instituciones que facilitaron este tipo de acumulación a menudo involucraban privilegios que interferían con la concreción de mercados neoclásicos, de allí que los annalistas braudelianos prestaran más atención a aquellos beneficios obtenidos por el uso de la coerción y la colusión. Al estar muchos de los grandes mercaderes que estudiaron dedicados al comercio de larga distancia, Braudel y sus seguidores se abocaron al estudio de la política internacional y a la relación de Europa con otras regiones (p. 15).

El siguiente recorte, extraído de la obra de Fernand Braudel La dinámica del capitalismo, publicada en francés en 1985, da cuenta del papel que le asignó Braudel a la institución mercado:

Por encima de la enorme masa de la vida material diaria, la economía de mercado ha tendido sus redes y mantenido vivos sus diversos entramados. Y fue, de ordinario, por encima de la economía de mercado propiamente dicha por donde prosperó el capitalismo.

3 Al respecto del "nacionalismo metodológico", los sociólogos Ulrich Beck y Natan Sznaider afirman que este subsume a las sociedades bajo el Estado-nación y reclaman un "cosmopolitismo metodológico" para el quehacer científico del siglo XXI. Por nacionalismo metodológico no debe entenderse una metodología específica, es un concepto de la teoría social, que abstrae como naturales o esenciales las sociedades nacionales o los Estados-nación, y, por lo tanto, son el objeto primario de análisis. 
El mercado no es sino un nexo imperfecto entre producción y consumo entre los siglos XV y XVIII, hay ciertos procesos que exigen un apelativo especial. Imagínense ustedes la enorme y múltiple capa que representan para una región determinada todos los mercados elementales con los que cuenta - una nube de puntos-, para ventas a menudo mediocres.

Por estas múltiples salidas comienza lo que denominamos la economía de intercambio, tendida entre el enorme campo de la producción y el del consumo, igualmente enorme.

Durante los siglos del Antiguo Régimen, entre 1400 y 1800, se trata aún de una economía de intercambio llena de imperfecciones.

Sin duda, y debido a sus orígenes, esta economía se pierde en la noche de los tiempos, pero no logra asociar toda la producción a todo el consumo, ya que una inmensa parte de aquélla se pierde en el auto-consumo, de la familia o del pueblo, y no entra en el circuito del mercado.

La economía de mercado constituye el nexo de unión, el motor, la zona estrecha pero viva en la que surgen las incitaciones, las fuerzas vivas, las novedades, las iniciativas, las múltiples tomas de conciencia, los desarrollos e incluso el progreso.

Todo lo que queda fuera del mercado no tiene sino un valor de uso, mientras que todo lo que traspasa su estrecha puerta adquiere un valor de intercambio.

Dos tipos de economía mercado (A y B), discernibles si les prestamos un poco de atención, aunque solo sea por las relaciones humanas, económicas y sociales que instauran.

En la primera categoría (A), incluiría de buen grado los intercambios cotidianos del mercado, los tráficos locales o a corta distancia, como el trigo y la madera que se encaminan hacia la ciudad cercana; e incluso los que tienen lugar en un radio más amplio, siempre que sean regulares, previsibles, rutinarios y abiertos, tanto a los pequeños, como a los grandes comerciantes: como por ejemplo los envíos de grano del Báltico desde Dantzig hasta Ámsterdam en el siglo XVII, o el tráfico del aceite y del vino del sur hacia el norte de Europa, y estoy pensando en aquellas "flotillas" de carros alemanes que venían a buscar, cada año, el vino blanco de Istria.

Comercio reglamentado, leal, trasparente, competitivo con productores, campesinos, intermediarios. La categoría $B$, que huye de la transparencia y del control, no se halla por completo ausente. Asimismo, el comercio regular que anima a los grandes "convoys" de trigo del Báltico es un comercio transparente: las curvas de precios a la salida de Dantzig y a la llegada a Ámsterdam son sincrónicas, y el margen de beneficios es a la vez seguro y moderado. Pero si se produce una carestía en el Mediterráneo, hacia 1590, por ejemplo, veremos a los mercaderes internacionales, representantes de importantes clientes, desviar de su ruta habitual a barcos enteros, cuyo cargamento, transportado a Liorna o a Génova, triplica o cuadruplica entonces 
sus precios. También en este caso, la economía A puede cederle el paso a la economía B. (2002, pp. 16-17)

De este modo, Fernand Braudel, embebido de una concepción neomaltusiana, encuentra en el mercado transregional la posibilidad de acumular riquezas. Esta capacidad de superar el estrecho marco analítico nacional es quizás una de las mayores originalidades del historiador francés, quien se verá obligado a crear un utillaje conceptual propicio a la realidad que pretendía describir, tal como el concepto economía mundo.

Immanuel Wallerstein se dejó influir por las propuestas braudelianas y las resignificó en una de las perspectivas de análisis globales más significativas del siglo XX, la Teoría del Análisis del Sistema Mundo. El sociólogo estadounidense reflexionó sobre la perspectiva del Sistema-mundo casi inmediatamente que fuera publicado el primer tomo de la célebre tríada sobre El moderno sistema mundial, en 1974, en su edición anglosajona. Sus aportes incidieron sobre aspectos metodológicos y epistemológicos de las ciencias sociales en general y sobre las concepciones del crecimiento económico hasta ese momento construidas. Cuestionó tanto la concepción generalizada de entender que el mundo está compuesto por múltiples sociedades como el punto de vista extendido del crecimiento económico propuesto por el desarrollismo (developmentalism), que asumía que todos los países eran intrínsecamente capaces de desarrollarse y obtener los resultados deseados.

Wallerstein se dio cuenta de que, pese a los estudios de los científicos sociales y los esfuerzos de las organizaciones internacionales, la brecha entre países desarrollados y en desarrollo no solo no se detuvo, sino que se agrandó después de la Segunda Guerra Mundial. La teoría se había vuelto inadecuada. De allí que propusiera la llamada perspectiva del Sistema-mundo como una alternativa explicativa.

Al respecto, en un artículo publicado en 1976, sostuvo que la diferencia clave entre la perspectiva del Sistema-mundo y el enfoque desarrollista sobre el crecimiento estaba en el punto de partida, en la unidad de análisis. Mientras que el desarrollismo asume que la unidad en la cual sucede principalmente la acción social es una unidad político-cultural -ya sea un Estado, una nación o pueblo, y se ocupaba de explicar las diferencias entre estas unidades-, la perspectiva del Sistema-mundo parte de entender que la acción social toma lugar en una entidad dentro de la cual se lleva a cabo una división del trabajo. Además, señaló que la acumulación continua de beneficios en el "centro", caracterizado por trabajo libre, requiere la continua existencia de pobreza, y generalmente periferias con trabajo no libre. La desigualdad entre "centro", "periferia" y"semiperiferia" es la garantía del crecimiento y la acumulación.

Pese a esta profunda renovación epistemológica y metodológica, el sociólogo estadounidense mantiene una explicación eurocéntrica. Para Wallerstein, el motor del crecimiento europeo es la particular combinación de trabajo libre, urbanización, comerciantes y gobiernos que facilitaron el comercio a larga distancia y la reinversión de las ganancias (Pomeranz, 2000, p. 15). 


\section{Hacia nuevas perspectivas no eurocéntricas}

A mediados de la década de 1990, estos cambios, mutaciones y desplazamientos en los modos de conocer de la historia económica generaron nuevas propuestas explicativas para comprender la dinámica económica de los tiempos modernos. La naciente perspectiva global comenzó a cuestionar e invalidar los antiguos enfoques caracterizados por el nacionalismo metodológico. Al respecto de esta mutación en los modos de asir las realidades pasadas, el historiador alemán Jürgen Kocka (2012) advierte que, aunque sobreviva el paradigma histórico clásico decimonónico, centrado en la perspectiva nacional, esta vieja alianza entre la historia como disciplina y el Estado-nación ya se ha perdido. ${ }^{4}$ Concluye respecto de la historia global que esta aparece en los trabajos historiográficos actuales en diferentes formas. A veces como el centro empírico de donde fluyen los datos, a veces como el medio con el cual son analizados determinados problemas históricos, o a veces simplemente como la perspectiva de análisis. Observa que el antieurocentrismo y la invitación a "provincializar" Europa o "re-orientar" la historia global constituyen rasgos característicos de los escritos de historia global, impulsados por las series de críticas que deconstruyeron los sentimientos europeos de superioridad y por el impacto del pensamiento poscolonial (pp. 1, 3 y 6$).^{5}$

Estas profundas transformaciones en los modos de conocer, desde el reconocimiento de los obstáculos interpretativos que genera el arraigo a la escala nacional hasta los cambios epistemológicos que trae consigo la perspectiva global, incidieron en los trabajos de Historia Económica. Lo estudios actuales cuestionan esta particular ejemplaridad de Occidente e ilustran que regiones de China tuvieron un semejante nivel de prosperidad entre 1680 y 1780 , que se expresó en la extensión de consumos de lujos en los hogares, en la intensificación del trabajo de mujeres y niños, en la expansión de los mercados.

Investigaciones demográficas desarrolladas en los años 1990 observaron que la originalidad occidental del matrimonio moderno declamada no era tal. James Lee, Cameron Campbell y Wang Feng mostraron que una significativa proporción de población no europea siguió un sistema demográfico semejante al descrito por Hajnal en Occidente (Bengtsson, Campbell, Lee et al., 2004).

El desarrollo de la historiografía asiática también aportó, con otro utillaje empírico, a desvanecer los relatos de certeza sobre la excepcionalidad del viejo continente. Las investigaciones asiáticas desplazaron el interrogante smithiano inicial. La historia económica comenzó a preguntarse por qué China declinó entre 1400 y 1980, y si su restablecimiento es un retorno a una preponderancia en la economía global. Bin Wong y Jean-Lauren Rosenthal (2011)

4 María Fernanda Justiniano, "Aportes de las perspectivas relacional y global a la historiografía de los tiempos modernos", http://www.academia.edu/8068394/Aportes_de_las_perspectivas_relacional_y_global_a_la_ historiograf\%C3\%ADa_de_los_tiempos_modernos

5 Con los términos "provincializar" y "re-orientar", Kocka nos remite a los seminales aportes de Dipesh Chakrabarty y André Gunder Frank, respectivamente. El historiador alemán, de este modo, nos aventura a pensar la historia global como una forma de conocimiento histórico, pero también como una metodología, una técnica, con alto contenido crítico-reflexivo, y por qué no, emancipador para las comunidades humanas globales. Además, observa, a partir desde su propia experiencia de historiador de Europa y de Alemania, durante la modernidad, que no necesariamente se debe ser un historiador global para sumar los aportes de la perspectiva global.

tiempo\&economía

Vol. 3 N $^{\circ} 1$ - I semestre de 2016

p. 31 
reclaman una explicación del éxito de Europa que incorpore tanto los tempranos procesos chinos como los recientes (p. x). Para estos autores, fueron la evolución política y económica del Sudeste Asiático y la larga preeminencia de Japón como segundo de la economía global los factores desencadenantes de las transformaciones disciplinares, a partir de 1980. Agregan que el éxito del crecimiento reciente de China no puede explicarse con las ideas e instituciones europeas, por cuanto estas son inadecuadas (p. 1).

En tanto, los estudios actuales indican que la región del delta del Yangtsé tuvo en la Edad Moderna condiciones de desarrollo semejantes a las de Inglaterra. A saber: mercados desarrollados, alto nivel de consumo, productividad de los hogares. Ambas regiones parecen haber crecido más bajo el impulso de Adam Smith que por la fuerza violenta de la proletarización de Marx. Sin dudas, el esclarecido desarrollo institucional pregonado por Max Weber y luego retomado por Douglas North perdió también poder para explicar la originalidad europea.

Las investigaciones sobre niveles de vida en Europa y Asia contribuyen a la necesaria revisión de los relatos eurocéntricos. En la compilación realizada en 2005, Robert Allen, Tommy Bengtsson y Martin Dribe concluyen que no existieron diferencias sistemáticas en los niveles de vida entre Europa y Asia antes de la Revolución Industrial. Para los compiladores del volumen, la afirmación se sostiene, desde la economía, la demografía y la vulnerabilidad al estrés económico (2005, p. 17). Afirman que:

Sin embargo, como varios de los aportes de este libro muestran, había importantes diferencias regionales en Asia durante el período preindustrial. Si bien las diferencias preindustriales en bienestar entre las partes más desarrolladas de Europa y Asia eran pequeñas, había diferencias sustanciales entre las partes más y menos desarrolladas en cada continente. Las pruebas de comparaciones detalladas a través de toda la gama de la experiencia no están disponible todavía. Podemos decir, sin embargo, que las comparaciones que se han hecho, que son generalmente para las partes más desarrolladas de Europa y China, no muestran la ventaja que esperaron Smith, Malthus y Marx. (p. 18)

A este estado de cosas se suma que la vía única e inglesa hacia la industrialización fue discutida por el historiador económico japonés Sugihara Kaoru (2007), quien entiende que existió también una vía oriental, que se dio en Japón, a partir de mediados del siglo XVIII, con la intensificación del trabajo campesino. La propuesta de Sugihara se sostiene en la obra de Akira Hayami, quien fue el artífice del concepto revolución industriosa, para referirse al proceso asiático de industrialización basada en la intensificación de la mano de obra, diferente al inglés.

Esta desmitificación del ascenso de Occidente tiene a Kenneth Pomeranz (2000) como uno de los principales artífices en el mundo historiográfico de la historia económica occidental. Los títulos de la obra y del capítulo introductorio dan cuenta de conceptos que nos ubican en una perspectiva global y relacional. Términos como conexiones y narraciones se introducen sin sonrojarse en este libro de historia económica de la Escuela de California, que posee además la característica singular de economizar el número de tablas y gráficos.

A diferencia de la historiografía europea del siglo $X X$, que dató los inicios del ascenso europeo al año mil, o después de la crisis del siglo XIV, Pomeranz señala desarrollos similares 
entre regiones de Asia y Europa. La divergencia de los desarrollos se producirá en el siglo XIX, en el contexto de un acceso privilegiado a los recursos de ultramar por parte de los europeos (p. 14).

Pomeranz toma distancia en su análisis de los aportes de Wallerstein. No comparte, por un lado, la centralidad asignada a Europa, antes de 1800, y, por otro, las estructuras temporoespaciales utilizadas, tales como centro y periferia. Insiste en que el mundo previo a la Revolución Industrial es policéntrico, con ausencia de un centro dominante. Afirma que solo después de la Revolución Industrial, Europa se convertirá en un centro hegemónico (p. 5).

Un lustro antes de estas aseveraciones, Dennis Flynn y Arturo Giráldez (1995) habían puesto en cuestionamiento las explicaciones de Wallerstein que asignaban a Europa una centralidad en el naciente sistema capitalista. Los investigadores de la universidad estadounidense de Hawái enfatizaron en el papel de intermediario que le cupo a Europa durante los primeros siglos de la Edad Moderna. Fue China, en el análisis de estos dos historiadores, quien ocupó el centro de la economía mundial.

Provocadoramente, los autores datan el nacimiento del comercio mundial en 1571, fecha en la que fue fundada la ciudad de Manila. A partir de entonces, afirman, puede hablarse de un mercado mundial coherente y completo. ${ }^{6}$ Más que ninguna otra commodity, es el mercado de la plata el que explica la emergencia de este comercio mundial. China fue la compradora dominante de plata en estos tiempos, y el Imperio español fue su principal proveedor, y Japón, el segundo.

Los estudios de Flynn y Giráldez se distancian notablemente de los, hasta entonces, sólidos constructos historiográficos elaborados por historiografía de la segunda posguerra, desde los marxistas hasta de los teóricos del análisis del sistema mundo. También revisan las

6 Estas nuevas certezas descritas impactan directamente sobre preguntas que adquirieron centralidad, en los tiempos en que vivimos. Una de ellas está referida a la datación del fenómeno de globalización. Jan Nederveen Pietersen (2012) distingue dos miradas respecto de este proceso, las que denomina visiones actuales y eurocéntricas, que fechan el inicio de la globalización en 1800, y las nombradas como del capitalismo, que hacen lo propio en 1500.

A diferencia de Immanuel Wallerstein, André Gunder Frank expresa que el sistema mundial actual tiene una historia al menos de 5000 años, en los cuales hubo acumulación de capital mediante una inversión infraestructural en agricultura, ganadería, transporte, comercio, defensa, educación. Sin embargo, entiende que hubo desde 1500 en adelante una única economía global con una división del trabajo mundial y comercio multilateral.

Kevin H. O'Rourke y Jeffrey G. Williamson afirman de modo contundente que la globalización no comenzó hace 5000 años, ni hace 500, sino durante las primeras décadas del siglo XIX. Entonces, la globalización no es un fenómeno moderno, sino propio de la modernidad, etapa en la que coincide la integración de los mercados, a partir de que convergen la distribución de los ingresos y el avance en los niveles de vida (2002).

Los planteos anteriores fueron cuestionados por Flynn y Giráldez, quienes priorizan las conexiones sobre los mercados, tanto para definir la globalización como para datar su origen. Entienden que es la amplitud geográfica de estas la que define la globalización. Estas conexiones son mucho más que vínculos comerciales. Son, también, relaciones ambientales, ecológicas, epidemiológicas, demográficas, entre otras.

De allí que afirmen que en el siglo XVI la globalización nació de nuevo. La humanidad se movió, se conectó, migró, desde el fin de la última Edad de Hielo. Fue el calentamiento global de hace 10.000 años el que aisló los continentes; y fue la expansión oceánica, a través de los océanos Atlántico y Pacífico, la que reconectó y dio inicio a la actual fase de globalización.

tiempo\&economía

Vol. $3 \mathrm{~N}^{\circ} 1$ - I semestre de 2016

p. 33 
interpretaciones de Hamilton sobre la revolución de los precios y discuten las tradicionales explicaciones sobre el ascenso y caída del Imperio español.

El análisis de las conexiones comerciales desde una perspectiva global posibilita deconstruir las afirmaciones que estructuraron el andamiaje de la visión eurocéntrica de la historia. Europa, a juicio de esta nueva óptica, tuvo un importante rol en el nacimiento del comercio mundial, pero su papel fue simplemente de intermediario en el vasto comercio de la plata. Masivas cantidades de este metal fueron transportadas por el Atlántico, a través del africano Cabo de Buena Esperanza, pero también fueron enormes las cantidades de plata llevadas por el Pacífico, desde Acapulco hasta Manila. Los datos son tomados de las mediciones de Te Paske, Barrett, Cross. Recuérdese que este último advierte sobre el comercio ilegal del siglo XV, que también implicó la transferencia de plata al Oriente desde Perú, por puertos no autorizados y desde la Colonia del Sacramento.

La economía china, fuertemente platificada desde el siglo XI, tanto monetaria como fiscalmente, se constituyó en una bomba que aspiró el metal a lo largo del globo, desde Europa, América, Japón. Esta voracidad, entonces, no es explicable por el déficit comercial europeo para adquirir productos como seda, porcelana, oro, especies, piedras preciosas, sino solo por la demanda de la economía de esta parte de Asia.

En un trabajo posterior, Flyn y Giráldez alertan que, para tener una idea más acabada del comercio mundial del siglo XIX, además de las conexiones comerciales observadas a través del flujo de plata, se hace necesario registrar el movimiento de la seda, principal producto de exportación de China (1996, pp. 52-68, 64). Japón e Hispanoamérica fueron los más importantes mercados a donde se dirigían los exquisitos tejidos chinos. La ciudad española de Manila y la portuguesa de Macao fueron los lugares donde se produjo el intercambio de plata y seda.

De este modo, el comercio de plata-seda proveyó de una importante estructura, hasta ahora, subterránea que conectó globalmente las economías de China, Japón, Macao, Manila, Taiwán, el Este asiático, Hispanoamérica, Europa y otras partes del mundo (1996, p. 65). No podría pensarse el éxito del Imperio de los Habsburgo durante la temprana Edad Moderna sin las posesiones de plata en América.

Estos nuevos y disruptivos planteos tienen eco en la producción latinoamericana que analiza los vínculos de los territorios americanos con Asia y Europa. Mariano Bonialian nos propone un Pacífico indiano, que desde mediados del siglo XVII hizo sentir su incidencia en el consumo de las sociedades de los virreinatos de Perú y Nueva España, que demandaban cada vez más bienes a cambio de plata (2013).

\section{A modo de conclusión}

En resumen, a partir de los años 1990 han tomado forma nuevos consensos que socavan las explicaciones dominantes del pasado occidental europeo y del extraeuropeo de los tiempos modernos. Podría afirmarse, junto a Sanjay Seth, que en los últimos veinte años se ha afirmado una política de conocimiento que desafía y escapa al eurocentrismo (2014, p. 311). 
Seguramente el éxito económico del Sudeste asiático, las tasas chinas de crecimiento, el desarrollo de la historiografía asiática, entre otros, podrían explicar este cambio de foco. También, "el fin de las certidumbres" y las ausencias de "flechas de la historia" tras los desmoronamientos de las utopías del siglo XX, entendiendo por estas últimas la idea de progreso y el socialismo real, que contribuyeron a una demanda de una lectura diferente de la empiria.

La Historia Económica y la Historia Moderna, ahora, no solo gozan en su haber de nuevos tópicos en sus respectivas agendas, sino que son las generadoras de estas grandes propuestas explicativas que aportan a esta nueva política de conocimiento no eurocéntrica, propia y característica de este nuevo siglo que se inicia.

Este mundo moderno dejó de ser eurocéntrico, para convertirse en policéntrico, en la mirada de Pomeranz, o asiacéntrico, desde el punto de vista de Flynn y Giráldez.

\section{Referencias}

Allen, R., Bengtsson, T. y Dribe, M. (2005). Living standards in the past. New perspectives on well-being in Asia and Europe. Nueva York: Oxford.

Amín, S. (1975 [1973]). ¿Cómo funciona el capitalismo? El intercambio desigual y la ley del valor. México: Siglo XXI.

Barrett, W. (1990). World Bullion Flows, 1450-1800. En Tracy, J. (ed.). The Rise of Merchant Empires: Long-Distance Trade in the Early Modern World, 1350- 1750, Cambridge, pp. 224-54.

Beck, U. y Sznaider, N. (2010). Unpacking cosmopolitanism for the social sciences: A research agenda. The British Journal of Sociology, 61, 381-403.

Bengtsson, T., Campbell, Lee, J. et al. (2004). Life under pressure. Mortality and living standards in Europe and Asia, 1700-1900. Londres: The MIT Press Cambridge.

Blaut, J. (1993). The colonizer's model of the world: Geographical diffusionism and Eurocentric history. Nueva York: Guilford.

Bonialian, M. (2013). El Pacífico hispanoamericano: política y comercio asiático en el Imperio español, 1680-1784. México: El Colegio de México.

Braudel, F. (2002 [1985]). La dinámica del capitalismo. México: FCE.

Brenner, R. (1988). Estructura de clases agraria y desarrollo económico en la Europa preindustrial. En T. H. Aston y C. H. E. Philpin (eds.), El debate Brenner. Estructura de clases agraria y desarrollo económico en la Europa preindustrial. Barcelona: Crítica, pp. 254-386.

Cachinero Sánchez, B. (1981). El modelo europeo de matrimonio, evolución, determinantes y consecuencias. Reis, 15, 33-58.

Crafts, N. (1985). British economic growth during the industrial revolution. Oxford: UPb.

Cross, H. (1983). "South American Bullion Production and Export, 1550-1750." En, Richards, J. F.

Precious Metals in the Later Medieval and Early Modern Worlds. Durham, pp. 397-424.

tiempo\&economía

Vol. $3 \mathrm{~N}^{\circ} 1$ - I semestre de 2016

p. 35 
De Vries, J. (1979). La economía de Europa en un período de crisis, 1600-1750. Madrid: Ediciones Cátedra.

De Vries, J. (1994). The industrial revolution. The Journal of Economic History, 54, 249-270.

De Vries, J. (2001). Economic growth before and after the industrial revolution. A modest proposal. En M. Prak (ed.), Early modern capitalism. Economic and social change in Europe, 1400-1800. Londres y Nueva York: Routledge, pp. 175-192

Flynn, D. y Giráldez, A. (1995). Born with a "silver spoon: The origin of world trade in 1571. Journal of World History, 6(2), 201-221

Flynn, D. y Giráldez, A. (1996). Silk for silver: Manila-Macao trade in the 17th century. Philippine Studies, 44(1), 52-68.

Frank, A. G. (1969). Latin America: Underdevelopment or revolution. Essays on the development of underdevelopment and the immediate enemy. Nueva York: Monthly Review Press.

Galeano, E. (1971). Las venas abiertas de América Latina. México: Siglo XXI.

Gerschenkron, A. (1962). Economic backwardness in historical perspective: A book of essays. Cambridge: Belknap Press of Harvard University Press.

Hajnal. J. (1974), European Marriage Patterns in Perspective, en D. V. Glass y D. E. C. Eversley (eds.), Population in History. Londres, Edward Arnold, pp. 101-143.

Hamilton, E. J. (1929). American Treasure and the Rise of Capitalism, 1500-1700. Economica 27, 338-357.

Hamilton, E. J. (1934). "American Treasure and the Price Revolution in Spain, 1501-1650". Nueva York, Octagon Books.

Harley, K. (1982). "British industrialization before 1841: Evidence of Slower Growth During the Industrial Revolution". The Journal of Economic History 42(2), 267-289.

Hayami, A. (1992). "The industrious revolution". Look Japan, 38(436), 8-10.

Jones, E. (2003 [1981]). The European miracle. Environments, economies and geopolicts in the history of Europe and Asia. Cambridge: Cambridge University Press.

Justiniano, M. F. (2012, noviembre). Aportes de la perspectiva relacional y global a la historiografía de los tiempos modernos y contemporáneos. Trabajo presentado en las VIII Jornadas de Historia Moderna y Contemporánea, organizada por la Facultad de Filosofía y Letras de la Universidad de Buenos Aires, Ciudad Autónoma de Buenos Aires. Disponible en https://www.academia.edu/8068394/Aportes_de_las_perspectivas_relacional_y_ global_a_la_historiograf\%C3\%ADa_de_los_tiempos_modernos

Kocka, J. (2012). Global history: Opportunities, dangers, recent trends. Culture \& History Digital Journal, 1 (1), doi:10.3989/chdj.2012.002.

Marx, K. (1946 [1867]). El capital. México: Siglo XXI.

North, D. y Thomas, R. (1991 [1973]). El nacimiento del mundo occidental. Una nueva historia económica (900-1700). Madrid: Siglo XXI. 
O' Rourke, K. H. \& Williamson, J. G. (2002). When did globalisation begin? European Review of Economic History, 6(1), 23-50.

Ogilvie, S. (2008). Proto-industrialización. En línea. Disponible en: http://www.econ.cam.ac.uk/ people/faculty/sco2/full-texts/Ogilvie-2008-Palgrave-proto-industrialization.pdf.

Pietersen, JN. (2012). Periodizing Globalization: Histories of Globalization. New Global Studies 6 (2). doi: 10.1515/1940-0004.1174

Piketty, T. (2014). El capital en el siglo XXI. Madrid: FCE.

Pomeranz, K. (2000). The great divergence. China, Europe and the making of the modern world economy. Princeton: Princeton University Press.Rostow, W. (1960). The five stages of growth-a summary. En The stages of economic growth: A non-communist manifesto. Cambridge: Cambridge University Press, pp. 4-16.

Seth, S. (2014). The Politics of knowledge: Or, how to stop being eurocentric. History Compass, 12(4), 311-320.

Smith, A. (1805). Investigación de la naturaleza y causas de la riqueza de las naciones. (Tomo I. Cap. VIII, $2^{\text {a }}$ ed, Trad. Josef Alonso Ortiz). Valladolid: Viuda e Hijos de Santander.

Smith, A. (1997). La teoría de los sentimientos morales. Madrid: Alianza Editorial.

Sugihara, K. (2007). The second Noel Butlin lecture: Labour-intensive industrialisation in global history. Australian Economic History Review, 47(2), 121-154.

TePaske, J. J. 1983. “New World Silver, Castile and the Philippines, 1590- 1800." En J. F. Richards (ed) Precious Metals in the Later Medieval and Early Modern Worlds, , Durham, pp. 425-46.

Van Zanden, J. L. (2001). Early modern economic growth: A survey of the European economy, 1500-1800. En M. Prak (ed.) Early modern capitalism. Economic and social change in Europe, 1400-1800. Londres y Nueva York: Routledge, pp. 67-84.Wallerstein, I. (1974). The modern world-system I: Capitalist agriculture and the origins of the capitalism. New York: Academic Press.

Wallerstein, I. (1976). A world-system perspective on the social sciences. Bristish Journal of Sociology, 27(3), 343-352.

Weber, M. (1996 [1922]). Economía y sociedad. México: Siglo XXI.

Williams, E. (1944). Capitalism and slavery. Richmond, Virginia: University of North Carolina Press.

Wong, R. B. y Rosenthal, J.-L. (2011). The politics of economic change in China and Europe. Londres: Harvard University Press. 